\title{
Is There a General Role for the Monkey Oculomotor System in Perceptual Decision-Making?
}

\author{
다 Yin Li and Kamesh Krishnamurthy \\ Neuroscience Graduate Group, Perelman School of Medicine, University of Pennsylvania, Philadelphia, Pennsylvania 19104 \\ Review of de Lafuente et al.
}

Sensory perception often requires our brains to interpret ambiguous information relayed by our sensory organs to form categorical decisions about the world (Gold and Shadlen, 2007; Kable and Glimcher, 2009). An influential paradigm for studying this interpretation process, known as a perceptual decision, involves combined electrophysiology and psychophysics in monkeys performing a randomdot motion (RDM) task (Newsome et al., 1989). For this task, a monkey is typically shown a cloud of moving dots with some dots moving coherently in one direction and the rest moving in random directions. The monkey's task is to decide the direction of the coherently moving dots and report this perceptual decision with an associated action, such as a leftward eye movement to report leftward motion. Neural correlates of the perceptual decision have been identified in the monkey oculomotor system. However, because the monkeys report their perceptual decisions using eye movements, the involvement of the oculomotor system may reflect the specific motor demands of this task, as has been observed in human fMRI experiments (Filimon et al., 2013). Alternatively, there might be a more general role of this system in perceptual decision-making.

Received May 11, 2015; revised June 12, 2015; accepted June 15, 2015. We thank Josh Gold for helpful comments.

The authors declare no competing financial interests.

Correspondence should be addressed to Yin Li, University of Pennsylva-

nia, Department of Neuroscience, 116 Johnson Pavilion, 3610 Hamilton Walk, Philadelphia, PA 19104. E-mail: yinli1@upenn.edu.

DOI:10.1523/JNEUROSCI.1818-15.2015

Copyright $\odot 2015$ the authors $\quad 0270-6474 / 15 / 359783-03 \$ 15.00 / 0$
Here, we review evidence in support of the latter hypothesis, with a focus on the lateral intraparietal area (LIP), an oculomotor area in the monkey posterior parietal cortex that has been studied extensively.

For the RDM and certain other tasks, performance is well described by accumulation-to-bound models in which noisy sensory evidence is accumulated over time into a quantity known as the decision variable, which represents the balance of evidence for or against a certain option (Palmer et al., 2005; Gold and Shadlen, 2007; Ratcliff and McKoon, 2008). The rate of rise of the decision variable is related to the strength of the sensory stimulus, with a steeper slope for more coherent motion. Decision commitment is triggered when this decision variable reaches a threshold (or bound) whose magnitude determines the speed-accuracy tradeoff.

In monkeys, neural correlates of the decision variable have been observed in a distributed network of oculomotor areas that includes the frontal eye field (FEF), area LIP, the superior colliculus (SC), and the caudate nucleus of the basal ganglia (Horwitz and Newsome, 1999; Kim and Shadlen, 1999; Shadlen and Newsome, 2001; Ding and Gold, 2010). Average firing rates of these neurons tend to ramp up from the time of stimulus onset until the monkey makes an eye movement to report its decision, with steeper ramps for stronger stimuli, as predicted by accumulation-to-bound models. These findings are in contrast to predictions of serial models of decision-making, in which an abstract decision is first computed and subsequently passed to motor areas for action selection. Rather, the same oculomotor areas planning the saccadic response also represent the evolving decision variable as it unfolds in time, leading some investigators to propose an intentional framework that recasts decision-making as a form of action selection (Gold and Shadlen, 2007; Cisek and Kalaska, 2010). To what extent, then, is the involvement of oculomotor areas like LIP in the decision process a consequence of the specific sensorimotor mappings used in RDM tasks, as opposed to a general role in perceptual decision-making that is saccade-independent?

Strikingly, even in tasks that dissociate the decision process from action planning, seemingly abstract, saccadeindependent representations of decisions have been observed in monkey oculomotor structures, including the superior colliculus, the supplementary eye field, and area LIP (Horwitz et al., 2004; Bennur and Gold, 2011). For example, one set of studies used a colored-targets task in which monkeys indicated their decision about motion direction by looking at targets of a particular color (e.g., red target for rightward motion, green for leftward motion) that appeared in unpredictable locations (Gold and Shadlen, 2003; Bennur and Gold, 2011). For this task, LIP neurons represent the perceptual decision within $\sim 200$ ms of motion stimulus onset, even when the target colors were not revealed until much later and thus the decision-related neural activity 
could not be attributed to saccadic planning (Bennur and Gold, 2011). Other studies have shown that LIP activity can also reflect arbitrary, learned visual categories in a manner that cannot be attributed to motor planning (Fitzgerald et al., 2011; Freedman and Assad, 2011). However, these earlier studies used either eye movements to indicate decisions or easily perceptible stimuli that did not necessarily require evidence accumulation to form the decision. What has been needed is a head-to-head comparison of activity in an oculomotor area like LIP on a difficult perceptual task using two different effectors for reporting decisions. A recent study by de Lafuente and colleagues (2015) in the Journal of Neuroscience fills this gap.

de Lafuente and colleagues (2015) trained monkeys to report decisions about motion direction using either a saccade or a reach. They recorded from area LIP as well as a nearby structure in the posterior parietal cortex, the medial intraparietal (MIP) area, which is not considered a part of the oculomotor system and is known to signal the location of objects that are targets of reaches (Snyder et al., 1997; Eskandar and Assad, 1999; Andersen and Cui, 2009). Saccade and reach trials were presented in alternate blocks and the appropriate effector was cued on each trial. This task design is well suited to test whether the recruitment of a particular motor area in perceptual decision-making is effector-specific, since the effector to be used was known at the start of each trial (de Lafuente et al., 2015, their Fig. 1).

Behavioral performance was indistinguishable for the two effector modalities and was consistent with an accumulationto-bound mechanism (de Lafuente et al., 2015, their Fig. 2). Task-driven patterns of neural activity in both LIP and MIP were also quite similar for the two modalities. For both brain areas and for both effector modalities average firing rate gradually ramped up as monkeys viewed motion stimuli that resulted in choices into neurons' preferred spatial locations, and the slope of this ramping depended on the strength of the motion stimulus, with steeper slopes for higher motion coherences (de Lafuente et al., 2015, their Fig. 7). Based on population firing rates alone, responses in both LIP and MIP were consistent with representing a decision variable for both effectors.

However, differences between the two areas emerged in terms of the secondorder statistics of spike trains, which has been used previously to differentiate evidence-accumulation from presaccadic bursts in area LIP (Churchland et al., 2011). This analysis assumes that singleunit spiking activity reflects a doubly stochastic process in which the total variance of the spike counts measured across trials can be partitioned into two parts: (1) point-process variability that would exist even if the underlying rate were identical across trials, and (2) trial-by-trial variability of the underlying rates. If an accumulation process generated the spike trains, then firing-rate variability would also be accumulated over time within a trial. Under a broad set of assumptions, this accumulated variability over time would lead to a linear increase of the second part of the across-trial variance. LIP passed this more stringent test for evidence accumulation for both saccade and reach tasks. In contrast, MIP passed this test only for the reach task (de Lafuente et al., 2015, their Fig. 9). Thus, LIP seems to represent the continuously evolving decision variable regardless of the modality used to report the choice, whereas MIP represents the decision variable only when the choice is indicated by reaches.

Several caveats temper the interpretation that LIP encodes an effector-general decision signal. First, LIP responses can be highly heterogeneous, with only a fraction of individual neurons exhibiting coherencedependent ramping (Meister et al., 2013). In de Lafuente et al. (2015), analyses of decision-like activity were done on normalized population responses. It would be interesting to see whether these results hold up in a unit-by-unit analysis and whether overlapping or distinct subpopulations of LIP neurons exhibit evidence accumulation for the two effectors.

Second, training history and experience in general can have a powerful effect on LIP responses (Freedman and Assad, 2006; Law and Gold, 2008). de Lafuente and colleagues (2015) trained their monkeys on the saccade task first, which may have resulted in a flow of motion input to LIP even when the oculomotor system is not required to solve the task. A related issue arises from the use of identical visual targets to signal choices with both effectors. Monkeys that are initially trained on the saccade task may continue to covertly plan saccades to those visual targets even on reach trials, consistent with an intentional framework of decision-making. Such a possibility would also be consistent with an attentional interpretation of LIP activity, which correlates with the spatial location to which animals are attending.
Recording from LIP in otherwise naive monkeys trained on a reach version of the colored-targets task might answer these questions.

Last, even though decision signals are observed in LIP on reach trials, it is not clear whether and how those signals relate to choices. Analysis of error trials would be informative in this regard. There are two types of observable errors: errors in the effector used and errors in the perception of the motion stimulus. Do LIP neurons still exhibit decision-related activity when monkeys mistakenly choose to respond with a hand movement? On reach error trials, are LIP responses predictive of monkeys' reach? Are MIP responses more predictive of reaches?

Despite these caveats, the results of de Lafuente and colleagues (2015) provide the most direct evidence to date that an oculomotor area encodes evidence accumulation regardless of the effector used to report decisions. It is not known whether these results extend to other oculomotor areas such as FEF and SC. Furthermore, it remains to be seen whether decision activity in oculomotor areas are also domaingeneral with respect to sensory modality (e.g., in auditory or vibrotactile tasks). Nevertheless, there is a striking convergence of evidence in the work reviewed here to suggest that the monkey oculomotor system, and area LIP in particular, plays a surprisingly general role in perceptual decision-making.

\section{References}

Andersen R, Cui H (2009) Intention, action planning, and decision making in parietal-frontal circuits. Neuron 63:568-583. CrossRef Medline

Bennur S, Gold JI (2011) Distinct representations of a perceptual decision and the associated oculomotor plan in the monkey lateral intraparietal area. J Neurosci 31:913-921. CrossRef Medline

Churchland A, Kiani R, Chaudhuri R, Wang X-J, Pouget A, Shadlen MN (2011) Variance as a signature of neural computations during decision making. Neuron 69:818-831. CrossRef Medline

Cisek P, Kalaska JF (2010) Neural mechanisms for interacting with a world full of action choices. Annu Rev Neurosci 33:269-298. CrossRef Medline

de Lafuente V, Jazayeri M, Shadlen MN (2015) Representation of accumulating evidence for a decision in two parietal areas. J Neurosci 35: 4306-4318. CrossRef Medline

Ding L, Gold JI (2010) Caudate encodes multiple computations for perceptual decisions. JNeurosci 30:15747-15759. CrossRef Medline

Eskandar EN, Assad JA (1999) Dissociation of visual, motor and predictive signals in parietal cortex during visual guidance. Nat Neurosci 2:88-93. CrossRef Medline

Filimon F, Philiastides MG, Nelson JD, Klooster- 
man NA, Heekeren HR (2013) How embodied is perceptual decision making? Evidence for separate processing of perceptual and motor decisions. J Neurosci 33:2121-2136. CrossRef Medline

Fitzgerald JK, Freedman DJ, Assad JA (2011) Generalized associative representations in parietal cortex. Nat Neurosci 14:1075-1079. CrossRef Medline

Freedman DJ, Assad JA (2006) Experiencedependent representation of visual categories in parietal cortex. Nature 443:85-88. CrossRef Medline

Freedman DJ, Assad JA (2011) A proposed common neural mechanism for categorization and perceptual decisions. Nat Neurosci 14: 143-146. CrossRef Medline

Gold JI, Shadlen MN (2003) The influence of behavioral context on the representation of a perceptual decision in developing oculomotor commands. J Neurosci 23:632-651. Medline

Gold JI, Shadlen MN (2007) The neural basis of decision making. Annu Rev Neurosci 30:535574. CrossRef Medline

Horwitz GD, Newsome WT (1999) Separate signals for target selection and movement specification in the superior colliculus. Science 284: 1158-1161. CrossRef Medline

Horwitz GD, Batista AP, Newsome WT (2004) Representation of an abstract perceptual decision in macaque superior colliculus. J Neurophysiol 91:2281-2296. CrossRef Medline

Kable JW, Glimcher PW (2009) The neurobiology of decision: consensus and controversy. Neuron 63:733-745. CrossRef Medline

Kim JN, Shadlen MN (1999) Neural correlates of a decision in the dorsolateral prefrontal cortex of the macaque. Nat Neurosci 2:176185. CrossRef Medline

Law CT, Gold JI (2008) Neural correlates of perceptual learning in a sensory-motor, but not a sensory, cortical area. Nat Neurosci 11:505513. CrossRef Medline

Meister ML, Hennig JA, Huk AC (2013) Signal multiplexing and single-neuron computations in lateral intraparietal area during decision-making. J Neurosci 33:2254-2267. CrossRef Medline

Newsome WT, Britten KH, Movshon JA (1989) Neuronal correlates of a perceptual decision. Nature 341:52-54. CrossRef Medline

Palmer J, Huk A, Shadlen M (2005) The effect of stimulus strength on the speed and accuracy of a perceptual decision. J Vis 5:376-404. Medline

Ratcliff R, McKoon G (2008) The diffusion decision model: theory and data for two-choice decision tasks. Neural computation 20:873922. CrossRef Medline

Shadlen MN, Newsome WT (2001) Neural basis of a perceptual decision in the parietal cortex (area LIP) of the rhesus monkey. J Neurophysiol 86:1916-1936. Medline

Snyder LH, Batista AP, Andersen RA (1997) Coding of intention in the posterior parietal cortex. Nature 386:167-170. CrossRef Medline 